\title{
Outcomes of blood loss post physiological birth with physiological management in the third stage of labour at a maternity home in Japan
}

\author{
Tokiko Oishi ${ }^{A, B} \mathrm{PhD}, \mathrm{MPH}, \mathrm{RN}, \mathrm{CNM} \cdot$ Tomoko Tamura $^{\mathrm{C}} \mathrm{PhD}, \mathrm{RN}, \mathrm{CNM}, \mathrm{PHN} \cdot$ Utako Yamamoto $^{\mathrm{D}}$
} RN, CNM.

${ }^{\mathrm{A}}$ Corresponding

Author: hopeful1@ hotmail.co.jp

${ }^{\text {B }}$ Takasaki University of Health and Welfare, Japan

${ }^{\mathrm{C}}$ Tokyo Medical University, Japan

D Yamamoto Maternity Home, Japan

\begin{abstract}
Background: Debate continues as to whether active or physiological management of the third stage of labour reduces the risk of postpartum haemorrhage for healthy well women. However, little attention has been paid to what volume of blood loss should be considered within normal range when the birth has been physiological, including physiological management of the third stage. At midwife-run maternity homes in Japan, midwives support physiological labour and birth, including the third stage, with protocols in place which govern when to intervene, refer and transfer to hospital obstetric care.
\end{abstract}

Objectives: To describe and quantify and gauge the significance of blood loss volume following birth when labour, birth and third stage have been physiological at one Japanese maternity home.

Method: Retrospective cohort study with data being extracted from the birth records of 512 women who gave birth at a maternity home between January 2007 and February 2010. Blood loss was measured up to two hours postpartum.

Findings: Among the 512 births, we determined the means of parity as $2.2(\mathrm{SD}=0.86)$, blood loss up to two hours post-delivery as $608.7 \mathrm{ml}(\mathrm{SD}=403.1)$, and length of the third stage of labour as $12.9 \mathrm{~min}$ $(\mathrm{SD}=7.7)$. Blood losses of between $0-499 \mathrm{ml}, 500-999 \mathrm{ml}, 1000-1499 \mathrm{ml}, 1500-1999 \mathrm{ml}$ and $\geq 2000 \mathrm{ml}$ were $52.3 \%, 31.6 \%, 11.3 \%, 4.1 \%$ and $0.6 \%$, respectively. Therapeutic intravenous uterotonics were provided to $3.1 \%$ of women when blood loss was $<1000 \mathrm{ml}$ but given to $83.3 \%$ when blood loss exceeded $1500 \mathrm{ml}$. Furthermore, $5.6 \%$ of the women received IV iron therapy when blood loss was $<1000 \mathrm{ml}$, while all the women did when blood loss exceeded $1500 \mathrm{ml}$. Mean haemoglobin level at four days postpartum with blood loss $>1500 \mathrm{ml}$ was $8.3 \mathrm{~g} / \mathrm{dl}(\mathrm{SD}=1.0)$ which was significantly lower than the mean of $9.8 \mathrm{~g} / \mathrm{dl}(\mathrm{SD}=1.2)$ calculated for the women who had a blood loss of $1000-1499 \mathrm{ml}$ and the $9.6 \mathrm{~g} / \mathrm{dl}$ mean $(\mathrm{SD}=0.9)$ for the women with a blood loss of $500-999 \mathrm{ml}(\mathrm{F}=27.92, \mathrm{p}<0.001)$. Of those reported $(n=11)$, mean haemoglobin levels in all groups increased to almost $11 \mathrm{~g} / \mathrm{dl}$ after two weeks.

Conclusion: Although these data are only from one maternity home in Japan, they clearly demonstrate that for these women, when births were physiological and the third stage was physiologically managed, blood loss during the third stage and up to two hours postpartum could be more than $500 \mathrm{ml}$ and may be as much as $1000 \mathrm{ml}$ without adversely affecting them.

Keywords: physiological birth, physiological (expectant) management of the third stage of labour, blood loss, maternity home, Japan

\section{INTRODUCTION}

Active management versus physiological management of the third stage of labour has been debated in the literature since the 1980s (Begley, 1990; Dixon, Fullerton, Begley, Kennedy, \& Guilliland, 2011; Jangsten, Mattsson, Lyckestam, Hellstrom, \& Berg, 2011; Prendiville, Harding, Elbourne, \& Stirrat, 1988; Rogers et al., 1998; Thilaganathan, Cutner, Latimer, \& Beard, 1993). Active management has been identified as consisting of three interventions: prophylactic uterotonic administration, early cord clamping before cord pulsation ceases, and controlled cord traction (Begley, Gyte, Devane, McGuire, \& Weeks, 2015). In physiological management the placenta is delivered spontaneously with the aid of gravity and sometimes by maternal effort without those three interventions (Begley et al., 2015).

In their Cochrane systematic review aimed at assessing the effectiveness of active or expectant management of the third stage of labour, Begley et al. (2015) found active management of the third stage reduced the risk of a haemorrhage greater than $1000 \mathrm{ml}$. They concluded that active management has benefits for women at mixed levels of risk for bleeding, although "there was an absence of high-quality evidence" (Begley et al., 2015, p.1), but that adverse effects were also identified. The studies included in the review involved births in hospital only settings with women often experiencing intervention during the first and second stages 
of labour, such as induction and /or augmentation of labour and instrumental delivery (Begley, 1990; Khan, John, Wani, Doherty, \& Sibai, 1997; Prendiville et al., 1988; Rogers et al., 1998).

In contrast, Dixon et al. (2011) conducted a systematic review aimed at assessing outcomes for low risk women who had a physiological labour and birth followed by physiological third stage care. The women included in this review had no interventions (such as induction/augmentation) during labour and birth. Using this definition Dixon et al. (2011) found four studies that met the review criteria. These demonstrated no increased risk of haemorrhage with physiological management and the authors then questioned the use of active management for low risk women. This review included a retrospective study from New Zealand of a cohort of low risk women who had had no interventions during labour and birth and had received physiological third stage care. Their findings indicated an increased risk of blood loss of more than $500 \mathrm{ml}$ with active management (Dixon et al., 2009).

Research studies to date have compared physiological and active management of the third stage with a focus on which method can reduce the volume of blood loss. With a blood loss volume of more than $500 \mathrm{ml}$ classed as a postpartum haemorrhage, the underlying assumption is that lower volumes are optimal for women. Throughout history, excessive blood loss during childbirth, with its resultant morbidity and mortality, has been one of the greatest concerns facing healthcare professionals. Consequently, emphasis has been put on the reduction of excessive blood loss during the third stage, yet little attention has been paid to what should be considered a normal range of blood loss volumes for a normal physiological birth.

Gyte (1992) suggested that blood loss at birth is "physiologically normal" and is part of the mechanism which brings the mother's blood volume back to its non-pregnant level. But how much is normal is debatable (Begley et al., 2015).

Postpartum haemorrhage (PPH) is defined by the World Health Organization (WHO) as a blood loss exceeding $500 \mathrm{ml}$. This definition is problematic (Cunningham \& Williams, 2001) because, if measured quantitatively, it transpires that a considerable number of women have a loss exceeding $500 \mathrm{ml}$. In one study, when chromium-labelled red blood cells were used to measure the blood volume lost from the circulation, 39\% of women had lost more than $500 \mathrm{ml}$ (Pritchard, Wiggins, \& Dickey, 1962). Another study by Brant (1967) used a washing machine extraction method and found that $21.5 \%$ of women had lost more than $500 \mathrm{ml}$ of blood at delivery. Newton, Mosey, Egli, Gifford, and Hull (1961) used the acid-hematin spectrophotometric method to identify the mean blood loss, of a cohort of primiparas without oxytocin after the delivery of the placenta, and the result was a mean of $613 \mathrm{ml}$.

Visual estimation is the most frequently practised method of judging blood loss during childbirth. Newton et al. (1961) and Brant (1967) compared visually estimated blood loss to measured blood loss and found that there was considerable underestimation, a finding replicated by others. Schorn (2010) reviewed 46 studies which compared actual measurement and estimated blood loss during childbirth, and found that visual estimation is inaccurate. She argues that estimated blood loss should be eliminated from routine assessment and documentation and that a combination of direct measuring and weighing is optimal.

Returning to the challenge of the current WHO definition of $\mathrm{PPH}$, a blood loss of more than $500 \mathrm{ml}$ may not necessarily be an abnormal event. Well-nourished, healthy women are able to compensate a blood loss of up to $1000 \mathrm{ml}$ (Blackburn, 2008;
Cunningham \& Williams, 2001; Frye, 2004). This is because the total blood volume during pregnancy can potentially increase by between $1400 \mathrm{ml}$ and $2000 \mathrm{ml}$ (Bloomfield \& Gordon, 1990; Cunningham \& Williams, 2001). In 1996 WHO refined its definition of PPH stating that blood loss of up to $1000 \mathrm{ml}$ could be considered physiological dependent on the woman's response to that loss (WHO, 1996).

In our study we consider that physiological blood loss during the third stage is the amount of blood that the woman's body sheds as a way of restoring equilibrium within the maternal circulation, during the transition from pregnancy hypervolemia to the nonpregnancy state.

Japanese independent midwives run their own maternity homes without needing a physician to be present. They are required by law to have a contract with a back-up physician and an institution. Only low risk women are supported to give birth in these maternity homes with a normal birth expected. Practice Guidelines for Maternity Homes (Japanese Midwives' Association, 2005, 2009) designate the criteria for whether a woman can have care from a midwife alone, needs co-management with a backup physician, or needs referral to an obstetrician. Well pregnant women, with a singleton fetus and cephalic presentation, are seen by an obstetrician during pregnancy and, if expected to be able to have a spontaneous vaginal birth, can be managed by midwives autonomously (Japanese Midwives' Association, 2005, 2009). In these circumstances midwives aim to support normal physiological birth of the baby and the placenta. The midwives take care of women throughout pregnancy, continuously nurturing women physically and mentally, to make physiological birth successful. Women are free of medical interventions and free to choose any position to give birth. No prophylactic uterotonics are used in the third stage, although some emergency medicines, such as uterotonics and intravenous infusions, and medical procedures can be used according to a given protocol with a back-up physician if haemorrhage occurs.

Midwifery-led maternity homes in Japan are unique places for childbirth in that medicine and /or medical procedures are prohibited by law. This study was prompted because the midwives working at one particular maternity home felt, overall, that the total blood loss in the women they provided care for without uterotonics, seemed to exceed what is traditionally defined as a PPH. However, almost all these women have an uneventful postpartum period.

Physiological labour, birth and third stage are more likely to occur in maternity homes, so exploring care provision and outcomes in this setting is likely to provide more understanding of what could be considered normal blood loss following physiological birth. Therefore, the aim of this study was to describe, quantify and gauge the significance of blood loss volume over a set time period, following birth when labour, birth and the third stage have been physiological within one midwifery-led maternity home in Japan.

\section{STUDY SETTING}

The maternity home in this study provides care for low risk women up to one month postpartum. This maternity home has about 150 births a year on average and six to seven midwives provide care to all women, rostering shifts to cover each 24 hours. The midwives share information about women closely and all the midwives get to know all the women, resulting in individualised and continuity of care from pregnancy through to the postpartum period.

All midwives are aware that they cannot give medicines within the maternity home and all are confident in managing a physiological 
third stage, including how and when to identify excessive blood loss. Health promotion and non-pharmaceutical care takes place throughout the antenatal period to help make physiological birth, including the third stage, possible.

The placenta is delivered spontaneously without either the administration of a prophylactic uterotonic agent or fundal massage or suprapubic pressure. After the baby is born and has been placed onto the mother's chest for skin to skin time, the umbilical cord is clamped and cut after making sure pulsation has ceased. Most women lie supine for the delivery of the placenta and are sometimes encouraged to push or squat.

In Japan, blood loss at birth is defined as the volume of blood lost within two hours of the birth, with haemorrhage being defined as a loss of more than $500 \mathrm{ml}$ (Japan Society of Obstetrics \& Gynecology, 2003). According to this definition, blood loss is measured at the end of the third stage, and then one hour and two hours later.

In our maternity home, when giving birth, the women are on three layers of collection sheets. The top layer is for amniotic fluid and is removed as soon as the baby is placed onto the mother's chest so that amniotic fluid is not mixed with blood loss. Then the placenta is delivered onto a second sheet which also collects the blood loss. Any extensive blood loss is collected on the third sheet, which is also weighed while the placenta is inspected. Any additional coagulated blood on the surface of the placenta is removed and placed onto the third sheet. Then all sheets are removed and weighed. The collection sheets are weighed before and after use. All gauzes and pads are also weighed before and after use. This constitutes the data collection at the end of third stage. Then a new pad is applied and then weighed after one hour, before being replaced with a second new pad which is weighed at the conclusion of the second hour. Total blood loss is then calculated to assess whether or not it was a haemorrhage.

This method has been routine practice at this maternity home and was introduced to ensure consistency of measurement. The midwives felt it was important to measure blood loss accurately to facilitate their decision-making process regarding the care they provided. In addition, the maternity home was a place of teaching, where consistent methods of delivering the placenta and measurement of blood loss had to be taught to all staff and students. According to a protocol agreed with the back-up physician, oral methylergometrine and/or IV oxytocin are available in the case of postpartum haemorrhage. Either can be administered during the delivery of the placenta or within one to two hours, depending on when bleeding occurs. Oral methylergometrine is administered when uterine atony occurs but is responding to care such as fundal massage and bleeding and the midwives consider the bleeding is likely to stop. For immediate heavy blood loss and/or continuous bleeding, IV oxytocin is administered. The midwives in attendance determine severity of blood loss from the nature and speed of blood flow, and the condition of the woman and whether the oral and/ or IV uterotonics should be used. Usually two midwives attend a birth so they can discuss the situation between them, thereby helping their decision-making process.

Haemoglobin $(\mathrm{Hb})$ is checked if the woman has had a blood loss of more than $1000 \mathrm{ml}$ (as per the protocol with the backup physician) or at the midwives' discretion if they consider the woman to be clinically anaemic. If $\mathrm{Hb}$ is lower than $10 \mathrm{~g} / \mathrm{dl}$ the physician will prescribe oral iron on the day of discharge (fifth day). IV iron can be also administered immediately after birth and in the postpartum period if a PPH has occurred. According to the protocol, if the woman has a blood loss of $1000 \mathrm{ml}$ or more, IV iron should be administered within one to two hours of the birth and every day up to the fourth day postpartum.

\section{METHOD}

This was a retrospective cohort study with data extracted from the birth records of the 512 women who gave birth at one Japanese maternity home between January 2007 and February 2010. Inclusion criteria were: low risk women with no major problem during pregnancy, singleton pregnancies, cephalic presentations and spontaneous onsets of labour between 37 weeks and 42 weeks. No medicine or medical procedures were used during the first or the second stages of labour for these 512 women. If either was required the woman was transferred to the back-up physician or the back-up institution and these women were excluded from this study.

The primary outcome of the study was blood loss volume during and following birth. The definition of blood loss has been described earlier. Blood loss was measured at the end of the third stage, and at one and two hours later. These measurements were added together to provide the total blood loss. Blood loss was measured and documented by midwives as a routine practice in the way described earlier. This documentation was then retrospectively analysed.

Secondary outcomes were: requirement for either oral or IV therapeutic uterotonic treatment, requirement for IV iron therapy, weight of baby, length of the third stage of labour, length of labour, parity, age, mother's body mass index (BMI, calculated as follows: weight $(\mathrm{kg}) \div\{$ height $(\mathrm{m}) \mathrm{x}$ height $(\mathrm{m})\})$, condition of placenta, perineal lacerations, postpartum $\mathrm{Hb}$ levels up to day four and at week two when reported. Changes in Hb levels, from the last antenatal $\mathrm{Hb}$ measurement to $\mathrm{Hb}$ levels at day four postpartum, were calculated.

\section{Data analysis}

Blood loss was divided into five groups by $500 \mathrm{ml}$ increments and then combined into four quartiles for the purpose of statistical analysis. Analysis included ANOVA, student t-tests, and Pearson's $r$, and all data were analysed using SPSS v12. A p value of $<0.05$ was considered to be statistically significant.

\section{Ethical consideration}

This study was approved by the Institutional Review Board of Tenshi College, Japan.

\section{FINDINGS}

\section{Demographics}

Demographics of the study participants are shown in Table 1.

\begin{tabular}{llll}
\multicolumn{2}{l}{ Table 1: Demographics } & & \\
& M (SD) & Range & $\mathrm{n}$ \\
\hline Age & $31.2(4.6)$ & $18-43$ & 512 \\
Parity & $2.2(0.9)$ & $1-5$ & 512 \\
Gestational age & $39 \mathrm{w} 6 \mathrm{~d}(7 \mathrm{~d})$ & $37 \mathrm{w} 0 \mathrm{~d}-42 \mathrm{wOd}$ & 512 \\
Woman's BMl & $20.4(2.4)$ & $15.6-35.3$ & 512 \\
Length of labour \& & $6 \mathrm{hr} 47 \mathrm{~min}$ & $50 \mathrm{~min}-$ & 512 \\
delivery & $(5 \mathrm{hr} 40 \mathrm{~min})$ & $53 \mathrm{hr} 07 \mathrm{~min}$ & \\
Length of 3rd stage & $12.9 \mathrm{~min}(7.7 \mathrm{~min})$ & $1 \mathrm{~min}-1 \mathrm{hr} 42 \mathrm{~min}$ & 512 \\
Newborn weight & $3162.1 \mathrm{~g}(343.7 \mathrm{~g})$ & $2100 \mathrm{~g}-4244 \mathrm{~g}$ & 511 \\
Apgar score at 1min & $9.0(0.78)$ & $4-10$ & 492 \\
\hline
\end{tabular}

These include mean age and parity of women, gestational ages, newborn birth weights, Apgar scores, lengths of the third stage and 
lengths of labour and delivery. The women who had been accepted to have their baby in the maternity home therefore were at low risk; however, there were three newborn and two maternal transfers.

\section{Blood loss}

Table 2: Blood Loss from completion of 3rd stage until 2 hours post birth

\begin{tabular}{|c|c|c|c|c|c|c|}
\hline & $M(S D)$ & & & & Range & $n$ \\
\hline At 3rd & $392.4 \mathrm{ml}$ & & & & 0-2070ml & 512 \\
\hline stage & (329.7ml) & & & & & \\
\hline \multirow[t]{2}{*}{1 hour } & $144.2 \mathrm{ml}$ & & & & $0-1120 \mathrm{ml}$ & 511 \\
\hline & (134.4ml) & & & & & \\
\hline \multirow[t]{2}{*}{2 hours } & $71.7 \mathrm{ml}$ & & & & $0-950 \mathrm{ml}$ & 509 \\
\hline & (101.2ml) & & & & & \\
\hline \multirow[t]{8}{*}{ Total $^{a}$} & $608.7 \mathrm{ml}$ & Parity & Total & $n$ & $92-2430 \mathrm{ml}$ & 512 \\
\hline & (403.1ml) & & blood & & & \\
\hline & & & loss & & & \\
\hline & & 1 & 610 & 106 & & \\
\hline & & 2 & 632.2 & 252 & & \\
\hline & & 3 & 566.3 & 121 & & \\
\hline & & 4 & 580 & 27 & & \\
\hline & & 5 & 584 & 6 & & \\
\hline
\end{tabular}

a. Total blood loss $=3$ rd stage +1 hour +2 hours

The mean blood loss at the end of the third stage of labour was $392 \mathrm{ml}$ and the mean total blood loss at two hours following birth was $608 \mathrm{ml}$ (Table 2). The sample consisted of almost $80 \%$ multiparas $(n=406)$, but there was no significant difference in

\begin{tabular}{llll}
\multicolumn{4}{l}{ Table 3: Identified differences in mean total blood loss } \\
& Intact (\%) & Not intact (\%) & P-value \\
\hline Perineum & $600.8 \mathrm{ml}$ & $615.1 \mathrm{ml}$ & $\mathrm{p}=.69$ \\
$\mathrm{n}=512$ & $\mathrm{n}=231(45)$ & $\mathrm{n}=281(54.9 \%)$ & \\
Placenta & $781.4 \mathrm{ml}$ & $608.8 \mathrm{ml}$ & $\mathrm{p}=.34$ \\
$\mathrm{n}=509$ a & $\mathrm{n}=504(99)$ & $\mathrm{n}=5(1 \%)$ & \\
Membranes & $718.4 \mathrm{ml}$ & $596.6 \mathrm{ml}$ & $\mathrm{p}=.33$ \\
$\mathrm{n}=481^{\text {b }}$ & $\mathrm{n}=471(97.9)$ & $\mathrm{n}=10(2 \%)$ & \\
\hline
\end{tabular}

a. Unrecorded (1) \& unclear status (2) were excluded from total of 512 b. Unrecorded (2) \& unclear status (29) were excluded from total of 512 c. Student t-test

total blood loss between primiparas and multiparas $(\mathrm{t}=-1.30$, $\mathrm{p}=0.19)$. Parity was not significantly associated with total blood loss $(\mathrm{F}=0.59, \mathrm{p}=0.67)$.

The placenta and the membranes were intact in $98.4 \%$ and in $92 \%$ of the births, respectively, and $45.1 \%$ of the perineums were intact (Table 3). Among women who had perineal lacerations
(54.9\%), 79.4\% ( $\mathrm{n}=223)$ had first degree and 20.6\% $(\mathrm{n}=58)$ had second degree lacerations. There were no third or fourth degree lacerations. The total blood loss was not associated with whether or not the placenta was intact $(\mathrm{t}=0.95, \mathrm{p}=0.34)$, the membranes were intact $(t=0.98, p=0.33)$, or the perineum was intact $(t=0.39$, $\mathrm{p}=0.69)$. (Table 3)

The total blood loss was positively correlated with the weight of the placenta $(r=0.29, p=0.00)$, the baby's weight $(r=0.20, p=0.00)$ and the woman's BMI $(\mathrm{r}=0.17, \mathrm{p}=0.01)$, and negatively correlated with the woman's age $(\mathrm{r}=-0.12, \mathrm{p}=0.01)$. The woman's BMI was also positively correlated with blood loss at one hour and two hours ( $\mathrm{r}=0.12, \mathrm{p}=0.01$, and $\mathrm{r}=0.16, \mathrm{p}=0.00$, respectively). The length of the third stage did not correlate with either blood loss at the end of third stage or total blood loss $(r=0.08, p=0.07$, and $\mathrm{r}=0.04, \mathrm{p}=0.39$, respectively). (Table 4)

Total blood loss volumes and uterotonic administration frequencies are shown in Table 5.

\begin{tabular}{|c|c|c|c|c|c|c|}
\hline \multirow[t]{2}{*}{ Total blood loss } & \multirow[t]{2}{*}{$n$} & \multirow[t]{2}{*}{$\%$} & \multicolumn{4}{|c|}{ Uterotonics } \\
\hline & & & Oral & $\%$ & IV & $\%$ \\
\hline $0-499 \mathrm{ml}$ & 268 & 52.3 & 13 & 4.9 & 0 & 0 \\
\hline $500-999 \mathrm{ml}$ & 162 & 31.6 & 36 & 27.2 & 5 & 3.1 \\
\hline 1000-1499ml & 58 & 11.3 & 30 & 51.7 & 15 & 25.9 \\
\hline $1500-1999 \mathrm{ml}^{\mathrm{a}}$ & 21 & 4.1 & \multirow{2}{*}{7} & \multirow{2}{*}{29.2} & \multirow{2}{*}{20} & \multirow{2}{*}{83.3} \\
\hline$\geq 2000 \mathrm{ml}^{\mathrm{a}}$ & 3 & 0.6 & & & & \\
\hline Total & 512 & 100 & 86 & 16.8 & 40 & 7.8 \\
\hline
\end{tabular}

a. Incidence of therapeutic use of uterotonics is combined for women who lost $1500-1999 \mathrm{ml}$ and $\geq 2000 \mathrm{ml}$

The majority of women in the cohort lost between $500 \mathrm{ml}$ and $999 \mathrm{ml}$ of blood and accounted for $84 \%$ of the total sample. Two of the mothers with excessive blood loss were transferred to hospital for management of their severe postpartum haemorrhages. The mean BMI of the women was compared over the four blood loss groups, $0-499 \mathrm{ml}, 500-999 \mathrm{ml}, 1000-1499 \mathrm{ml}$ and $\geq 1500 \mathrm{ml}$ and were $20.1,20.7,20.5$ and 20.7 respectively, with no significant differences among the groups $(\mathrm{F}=2.49, \mathrm{p}=0.06)$.

\section{Therapeutic use of uterotonics}

Of the women who had a blood loss of less than $1000 \mathrm{ml}$, one third $(32.1 \%)$ were given oral therapeutic uterotonics (Table 5) and $3.1 \%$ were given IV uterotonics. The majority of women who had blood loss of $1000-1499 \mathrm{ml}$ were given oral therapeutic uterotonics with $25.9 \%$ being given IV. In contrast, almost all the women who lost more than $1500 \mathrm{ml}$ of blood needed oral and/or IV therapeutic uterotonics. Overall, $7.8 \%$ of the cohort needed IV uterotonics.

\begin{tabular}{|c|c|c|c|c|c|c|c|}
\hline & $\begin{array}{l}\text { Total blood } \\
\text { loss }\end{array}$ & Fall in $\mathrm{Hb}^{a}$ & $\begin{array}{l}\text { Weight of } \\
\text { placenta }\end{array}$ & Woman's BMI & Woman's age & $\begin{array}{l}\text { Length of } 3 r d \\
\text { stage }\end{array}$ & Parity \\
\hline Fall in $\mathrm{Hb}^{a}$ & $0.40^{* *}$ & - & & & & & \\
\hline Weight of placenta & $0.29 * *$ & -0.04 & - & & & & \\
\hline Woman's BMI & $0.12^{* *}$ & 0.00 & $0.20 * *$ & - & & & \\
\hline Woman's age & $-0.12^{* *}$ & 0.05 & -0.07 & $.092 *$ & - & & \\
\hline Length of 3rd stage & 0.04 & -0.01 & 0.02 & -0.02 & $-0.10^{*}$ & - & \\
\hline Parity & -0.04 & -0.13 & -0.07 & $0.11^{*}$ & $0.41^{* *}$ & -0.07 & - \\
\hline
\end{tabular}

a. Fall in $\mathrm{Hb}=$ last antenatal $\mathrm{Hb}-\mathrm{Hb}$ at 4 days postpartum, ${ }^{*} \mathrm{p}<.05,{ }^{* *} \mathrm{p}<.001$ 


\section{Haemoglobin levels in the postpartum period}

\begin{tabular}{|c|c|c|c|c|c|c|c|c|}
\hline \multirow[t]{2}{*}{ Total blood loss } & \multirow[b]{2}{*}{$\mathrm{n}(\%)$} & \multirow{2}{*}{$\begin{array}{l}\text { IV iron } \\
\mathrm{n}(\%)\end{array}$} & \multicolumn{2}{|c|}{$\mathrm{Hb}$ at $\mathrm{D} 4^{\mathrm{a}}$} & \multicolumn{2}{|c|}{ Fall in $\mathrm{Hb}^{\mathrm{b}}$} & \multicolumn{2}{|c|}{$\mathrm{Hb}$ at $\mathrm{W}^{\mathrm{a}}$} \\
\hline & & & $n$ & $M(S D)$ & $n$ & $M(S D)$ & $\mathrm{n}$ & $M(S D)$ \\
\hline $0-499 \mathrm{ml}$ & $268(52.3)$ & $0(0)$ & & & & & & \\
\hline $500-999 \mathrm{ml}$ & $162(31.6)$ & $9(5.6)$ & 15 & $9.6(0.9)^{* *}$ & 15 & $1.44(0.35)^{* *}$ & 4 & $11.0(0.8)$ \\
\hline $1000-1499 \mathrm{ml}$ & 58 (11.3) & 44 (75.9) & 56 & $9.8(1.2)^{* *}$ & 56 & $1.68(0.18)^{* *}$ & 4 & $10.8(1.1)$ \\
\hline $1500-1999 \mathrm{ml}^{\mathrm{c}}$ & $21(4.1)$ & 241001 & 23 & 83 & 23 & 3201020 & 7 & 10 \\
\hline$\geq 2000 \mathrm{ml}^{\mathrm{c}}$ & $3(0.6)$ & $24(100)$ & 23 & $8.3(1.0)$ & 23 & $3.22(0.24)$ & 7 & $10.8(1.1)$ \\
\hline Total & $512(100)$ & 77 (15) & & & & & & \\
\hline
\end{tabular}

a. ANOVA(Bonferroni) $\quad{ }^{* *} \mathrm{p}<.001$

b. Fall in $\mathrm{Hb}=$ last antenatal $\mathrm{Hb}-\mathrm{Hb}$ at 4 days postpartum

c. Incidence of therapeutic use of uterotonics is combined for women who lost $1500-1999 \mathrm{ml}$ and $\geq 2000 \mathrm{ml}$

The numbers of women who had an $\mathrm{Hb}$ taken and/or were treated for anaemia are provided in Table 6. IV iron was administered to $5.6 \%$ of the women who had had a blood loss of less than $1000 \mathrm{ml}$, and to $75.9 \%$ of the women who had had a blood loss of 1000 $1499 \mathrm{ml}$. All of the women with a blood loss of more than $1500 \mathrm{ml}$ received iron therapy.

The mean $\mathrm{Hb}$ level at four days postpartum for women with a blood loss $\geq 1500 \mathrm{ml}$ was $8.3 \mathrm{~g} / \mathrm{dl}(\mathrm{SD}=1.0)$. This was significantly lower than the $9.8 \mathrm{~g} / \mathrm{dl}(\mathrm{SD}=1.2)$ found for women who had a blood loss of $1000-1499 \mathrm{ml}$ and the $9.6 \mathrm{~g} / \mathrm{dl}(\mathrm{SD}=0.9)$ for women with a loss of $500-999 \mathrm{ml}(\mathrm{F}=27.92, \mathrm{p}<.001)$.

The decreases in $\mathrm{Hb}$ level between the last antenatal check and at four days postpartum were compared among the three groups of blood loss (Table 6). The mean decrease in $\mathrm{Hb}$ levels was significantly higher for women who had a blood loss of $\geq 1500 \mathrm{ml}$ than the mean decrease in the women whose blood loss was $1000-1499 \mathrm{ml}$ or $500-999 \mathrm{ml}(\mathrm{F}=11.90, \mathrm{p}<.001)$. There was no significant difference in the decrease of mean hemoglobin levels with a blood loss of 500-999 ml compared to a blood loss of 1000$1499 \mathrm{ml}$ (Table 6).

Regardless of the woman's blood loss, by two weeks postpartum $\mathrm{Hb}$ levels were almost $11 \mathrm{~g}$ with or without iron therapy and there were no statistically significant differences among the groups $(\mathrm{F}=0.66, \mathrm{p}=0.54)$.

\section{Other events affecting mothers and newborns}

Three newborn transfers occurred. Two were due to respiratory problems and one was due to a persistent fever. Phototherapy for jaundice was given to $2.0 \%(n=10)$ babies. At two weeks postpartum $93.8 \%$ of mothers were breastfeeding completely, $2.1 \%$ were breastfeeding partially and $2(0.4 \%)$ women were using formula only. Breastfeeding status was not associated with total blood loss ( $\mathrm{t}=1.52, \mathrm{p}=0.13)$.

\section{DISCUSSION}

In our study, the women were healthy and no interventions took place throughout the first, second and third stages of labour and birth. We found that approximately half $(52 \%)$ of our cohort had a total blood loss of less than $500 \mathrm{ml}$ and a further $32 \%$ had a blood loss of $500-999 \mathrm{ml}$. Therefore, the majority $(84 \%)$ of this normal low risk cohort had a total blood loss, at two hours following the birth, of less than $1000 \mathrm{ml}$, with an average of $608 \mathrm{ml}$. Parity and first and second degree lacerations did not affect the blood loss volume. Furthermore, there were only two obese (BMI>30) women in our study.

Therapeutic intravenous uterotonics were administered to $3.1 \%$ of women when blood loss was $<1000 \mathrm{ml}$ but given to $83.3 \%$ when the loss exceeded $1500 \mathrm{ml}$.
Blood loss in our study appears to be higher than what has traditionally been considered normal but adverse effects were not apparent unless the women had a blood loss of $\geq 1500 \mathrm{ml}$, at which time the mean $\mathrm{Hb}$ level was significantly lower when compared to other blood loss volumes. In addition, for this group, the decrease in $\mathrm{Hb}$ levels in the early postpartum stage when compared to the last antenatal $\mathrm{Hb}$ level was also significantly larger.

Our findings are consistent with other studies that suggest women can tolerate a blood loss of up to $1000 \mathrm{ml}$ without this having any long term impact on their health (Blackburn, 2008; Bloomfield \& Gordon, 1990; Frye, 2004; Gyte, 1992).

The results of our study differ from those reported by the studies reviewed by Dixon et al. (2011). In this review Thilaganathan et al. (1993), Dixon et al. (2009) and Bais, Eskes, Pel, Bonsel and Bleker (2004) reported mean blood losses of $200 \mathrm{ml}, 213.6 \mathrm{ml}$ and $361 \mathrm{ml}$, respectively. The wide variation may be due to timing of blood loss measurement in each study.

A Swedish randomised controlled trial (Jangsten et al., 2011), comparing blood loss dependent on third stage care, compared actively and physiologically managed third stage of labour and found very similar results to our study in the physiologically managed arm. The average blood loss was reported as $680 \mathrm{ml}$ and losses of more than $1000 \mathrm{ml}$ occurred in $16.8 \%$ of the physiologically managed arm.

In our study and in the Swedish study, blood loss was measured for up to two hours following the birth. Whereas, both the Thilaganathan et al. (1993) and the Dixon et al. (2009) studies used estimated loss immediately following the birth. The timing of blood loss measurement was unclear in the study by Bais et al. (2004).

Despite this difference in timing, if blood loss measures are compared for immediately following the birth, the mean loss for Jangsten et al. (2011) was $395 \mathrm{ml}$ and in our study $392 \mathrm{ml}$, both of which are higher than the estimated values of the other studies (Bais et al., 2004; Dixon et al., 2009; Thilaganathan et al., 1993).

A potential reason for the higher recorded blood loss volume is the method of blood loss measurement. There is evidence that visual estimation results in either over or underestimation of blood loss. When the loss is small, it is more likely to be overestimated and when large it is more likely to be underestimated (Al-Kadri et al., 2014; Dildy, Paine, George, \& Velasco, 2004; Newton et al., 1961; Razvi, Chua, Arulkumaran, \& Ratnam, 1996; Wallace, 1967). Brant (1967) found that when the visually estimated loss exceeded $300 \mathrm{ml}$, underestimation was invariable. Razvi et al. (1996) also found that the tendency to underestimate blood loss was greatest when the measured blood loss was greater than 
$300 \mathrm{ml}$. It is also possible, because traditional teaching may have influenced blood loss measurement with the expectation that the range for normal blood loss is $200-300 \mathrm{ml}$, that this is indeed why most of the estimated losses fell into the $200-300 \mathrm{ml}$ range. It is possible that the visually estimated volumes reported by the Thilaganathan et al., (1993), Dixon et al., (2009) and Bais et al., (2004) studies, were underestimated since they were gauged subjectively and not quantitatively.

Our study and the Swedish study (Jangsten et al., 2011) have sought to measure blood loss with a high degree of accuracy. In the case of the Swedish study, soaked pads with amniotic fluid were removed and a dry sanitary pad was placed under the mother immediately after the birth of the baby, and all sanitary towels and pads were weighed before and after use. In our study, not only was there a protocol for measurement, but there was also consistency of midwifery staff. The method of measurement was consistently taught to all midwifery staff and attending students in the maternity home carrying out the measuring, which has potentially contributed to the accuracy of the measurements.

Despite these similarities there were some differences between our study and that of Jangsten et al. (2011). In the latter study medical interventions (such as epidural and augmentation) were included in the physiological arm of their study. This could have confounded their results. However, of importance are the similarities between blood loss volumes and rate of occurrence of severe PPH in these two studies.

\section{Therapeutic use of uterotonics, and iron and haemaglobin levels}

A third of women in our study had a total blood loss of 500-999 ml, did not require therapeutic uterotonics or IV iron replacement and had no clinically signs of anaemia following birth. For women who had a blood loss of 1000-1499ml, one quarter were treated with IV uterotonics and the majority $(75.9 \%)$ were treated with IV iron, resulting in improved $\mathrm{Hb}$ levels postpartum. For those women who had a blood loss volume of more than $1500 \mathrm{ml}$, almost all needed therapeutic uterotonics and IV iron replacement. Despite these treatments, their $\mathrm{Hb}$ levels were significantly lower than the levels of the other groups. Furthermore, a loss of $\geq 1500 \mathrm{ml}$ brought about a significantly greater decrease in $\mathrm{Hb}$ levels compared to the last antenatal $\mathrm{Hb}$ level, suggesting that the level above which immediate intense treatment is required for all women, regardless of their condition antenatally, is this litre and a half level. Lilley et al. (2015) also found that gravimetric measurement of blood loss was correlated with a fall in $\mathrm{Hb}$ following $\mathrm{PPH}$ where blood loss exceeded $1500 \mathrm{ml}$. They hypothesise that when blood loss exceeds $1500 \mathrm{ml}$, the protective, physiological adaptation of pregnancy is less effective. Our findings are supportive of this hypothesis.

Uterotonics and/or iron were given at the midwives' discretion. Therefore, an individual midwife's perspective can potentially influence treatment given. Our results show that, despite a culture of not using medication unless necessary, the midwives made appropriate assessments and decisions which supported the wellbeing of women.

\section{Physiology of blood loss after pregnancy- induced hypervolemia}

Cunningham and Williams (2001) argue that when blood loss is measured accurately, a volume in excess of $500 \mathrm{ml}$ is not necessarily an abnormal event. Bloomfield and Gordon (1990) agree, suggesting that a fit young woman can cope with a blood loss of up to $1000 \mathrm{ml}$ without difficulty because she has increased her circulating blood volume by more than this during pregnancy. During pregnancy a woman increases her blood volume by 30 $60 \%$ which for an average-sized woman amounts to $1000-2000 \mathrm{ml}$ (Cunningham \& Williams, 2001). Consequently, a woman can tolerate blood loss at delivery approaching the volume of blood she added during pregnancy, without any remarkable decrease in postpartum hematocrit (Cunningham \& Williams., 2001). Therefore, blood loss up to $1000 \mathrm{ml}$ may be considered physiological in women who are well nourished and can be considered healthy (World Health Organization, 1996).

Newton et al. (1961) argue that the height and weight of the mother may be related to her response to blood loss during third stage. A non-pregnant woman's circulating blood volume can be calculated as half of [height (inches) $\times 50]+[$ weight (pounds) $\times 25$ ] and pregnant blood volume increase varies from $30-60 \%$ of calculated non-pregnant volume (Cunningham \& Williams, 2001). In our study, BMI was correlated with blood loss at one hour, two hours and total blood loss. Bloomfield and Gordon (1990) point out that the definition of haemorrhage as a blood loss of $500 \mathrm{ml}$ or more does not make allowance for the size of the circulating blood volume of the individual mother.

Some studies in the literature report BMI $>30$ as a risk factor for excessive blood loss (Fyfe, Thompson, Anderson, Groom, \& McCowan, 2012; Schrauwers \& Dekker, 2009). Nevertheless, in our study there was no significant association between mean BMI and excessive blood loss. However, compared to Western populations, the prevalence of obesity is much lower in Japan, especially among women giving birth at maternity homes. This is demonstrated by the fact that only two women in our study were classified as obese, therefore our finding cannot be generalised to other populations with a higher prevalence of obesity. Further research is necessary to investigate whether a woman's BMI and blood loss are associated physiologically and how we should take this into consideration when we decide how much blood loss constitutes the normal range for an individual woman.

This is the first study to evaluate blood loss up to two hours postpartum at a maternity home outside of a hospital setting in Japan. In hospitals, prophylactic uterotonics are routinely used and active management is prevalent, though many variations exist. No other study has been published on blood loss with physiological management of the third stage following physiological birth in Japan to date.

A strength of this study is the consistency of the method of, and the personnel involved in, the measurement of blood loss volume. We found that the total mean blood loss at two hours postpartum was greater than $500 \mathrm{ml}$ (therefore, technically defined as a PPH). Our findings provide a baseline for future research aimed at identifying normative blood loss volumes when birth is physiological and the third stage is physiologically managed.

Blood loss of $\geq 1500 \mathrm{ml}$ seemed critical with two maternal transfers and significant falls from the last antenatal $\mathrm{Hb}$ levels postpartum. However, almost all women were breastfeeding and recovering well with $\mathrm{Hb}$ levels returning to normal levels at two weeks postpartum.

\section{LIMITATIONS}

This is a retrospective cohort study which was conducted at one maternity home in Japan. The findings of this study cannot be 
generalised to other maternity homes. Larger studies are necessary to fully evaluate the normal range of blood loss with physiological management following physiological labour and birth.

$\mathrm{Hb}$ levels were not taken from all the women in our cohort. Only women who lost more than $1000 \mathrm{ml}$ of blood and those who looked clinically anaemic, even if they had a blood loss of less than $1000 \mathrm{ml}$, had samples taken. Any further study should evaluate all women's $\mathrm{Hb}$ levels to judge the effect of blood loss volume.

\section{CONCLUSION}

Although these data come only from one maternity home in Japan, they record exact quantities of blood loss at the third stage and up to two hours postpartum, and the results suggest that blood loss volumes of $500-1000 \mathrm{ml}$ may be physiologically normal when births are physiological and the third stage is physiologically managed.

Further research is needed to understand the physiology of the blood loss that accompanies childbirth and the physiological reaction to that blood loss, so that we can develop appropriate guidelines for identifying and treating pathological haemorrhage and the administration of therapeutic uterotonics when the birth has been physiological.

\section{CONFLICT OF INTEREST STATEMENT}

The authors report no conflict of interest.

\section{REFERENCES}

Al-Kadri, H. M., Dahlawi, H., Al Airan, M., Elsherif, E., Tawfeeq, N., Mokhele, Y., ... Tamim, H. M. (2014). Effect of education and clinical assessment on the accuracy of post partum blood loss estimation. BMC Pregnancy and Childbirth, 14, 110. http://dx.doi.org/10.1186/14712393-14-110

Bais, J. M. J., Eskes, M., Pel, M., Bonsel, G. J., \& Bleker, O. P. (2004). Postpartum haemorrhage in nulliparous women: Incidence and risk factors in low and high risk women. A Dutch population-based cohort study on standard $(>$ or $=500 \mathrm{ml})$ and severe $(>$ or $=1000 \mathrm{ml})$ postpartum haemorrhage. European Journal of Obstetrics \& Gynecology and Reproductive Biology, 115(2), 166-172. http://dx.doi.org/10.1016/j. ejogrb.200312.008

Begley, C. M. (1990). A comparison of 'active' and 'physiological' management of the third stage of labour. Midwifery, 6(1), 3-17.

Begley, C. M., Gyte, G. M., Devane, D., McGuire, W., \& Weeks, A. (2015). Active versus expectant management for women in the third stage of labour. Cochrane Database Systematic Review, 3, CD007412. http://dx.doi.org/10.1002/14651858.CD007412.pub4

Blackburn, S. (2008). Physiological third stage of labour and birth at home. In J. Edwins (Ed.), Community Midwifery Practice (pp. 66-86). Oxford,UK: Blackwell Publishing.

Bloomfield, T. H., \& Gordon, H. (1990). Reaction to blood loss at delivery. Journal of Obstetrics and Gynaecology, 10(2), s13-s16. http:// dx.doi.org/10.3109/01443619009151299

Brant, H. A. (1967). Precise estimation of postpartum haemorrhage: difficulties and importance. BMJ, 1(5537), 398-400.

Cunningham, F. G., \& Williams, J. W. (2001). Williams Obstetrics (21st ed.). New York, USA: McGraw-Hill.

Dildy, G. A., III, Paine, A. R., George, N. C., \& Velasco, C. (2004). Estimating blood loss: can teaching significantly improve visual estimation? Obstetrics \& Gynecology, 104(3), 601-606. http://dx.doi. org/10.1097/01.aog.0000137873.07820.34

Dixon, L., Fletcher, L., Tracy, S. K., Guilliland, K., Pairman, S., \& Hendry, C. (2009). Midwives care during the Third Stage of Labour: An analysis of the New Zealand College of Midwives Midwifery Database 2004-2008. New Zealand College of Midwives Journal, 41, 20-25.

Dixon, L., Fullerton, J. T., Begley, C., Kennedy, H. P., \& Guilliland, K. (2011). Systematic review: the clinical effectiveness of physiological (expectant) management of the third stage of labor following a physiological labor and birth. International Journal of Childbirth, 1(3), 179-195.
Frye, A. (2004). Holistic Midwifery: A Comprehensive Textbook for Midwives in a Homebirth Practice (Vol. 2). Portland, USA: Labrys Press.

Fyfe, E. M., Thompson, J. M., Anderson, N. H., Groom, K. M., \& McCowan, L. M. (2012). Maternal obesity and postpartum haemorrhage after vaginal and caesarean delivery among nulliparous women at term: a retrospective cohort study. BMC Pregnancy \& Childbirth, 12, 112. http://dx.doi.org/10.1186/1471-2393-12-112

Gyte, G. (1992). The significance of blood loss at delivery. MIDIRS Midwifery Digest, 2, 88-92.

Jangsten, E., Mattsson, L. A., Lyckestam, I., Hellstrom, A. L., \& Berg, M. (2011). A comparison of active management and expectant management of the third stage of labour: a Swedish randomised controlled trial. BJOG: An International Journal of Obstetrics and Gynaecology, 118(3), 362-369. http://dx.doi.org/10.1111/j.14710528.2010.02800.x

Japan Society of Obstetrics \& Gynecology (Eds) (2003). Obgyn Technical Terms and Glossary Collection. Tokyo: Kanehara Publishing.

Japanese Midwives' Association (Eds) (2005). Practice guidelines for maternity homes. Tokyo: Japanese Midwives' Publishing Corporation.

Japanese Midwives' Association (Eds) (2009). Practice guidelines for maternity homes revised. Tokyo: Japanese Midwives' Publishing Corporation.

Khan, G. Q., John, I. S., Wani, S., Doherty, T., \& Sibai, B. M. (1997). Controlled cord traction versus minimal intervention techniques in delivery of the placenta: a randomized controlled trial. American Journal of Obstetrics \& Gynecology, 177(4), 770-774.

Lilley, G., Burkett-St-Laurent, D., Precious, E., Bruynseels, D., Kaye, A., Sanders, J., ... Collis, R. E. (2015). Measurement of blood loss during postpartum haemorrhage. International Journal of Obstetric Anesthesia, 24(1), 8-14. http://dx.doi.org/10.1016/j.ijoa.2014.07.009

Newton, M., Mosey, L. M., Egli, G. E., Gifford, W. B., \& Hull, C. T. (1961). Blood loss during and immediately after delivery. Obstetrics \& Gynecology, 17, 9-18.

Prendiville, W. J., Harding, J. E., Elbourne, D. R., \& Stirrat, G. M. (1988). The Bristol third stage trial: active versus physiological management of third stage of labour. BMJ, 297(6659), 1295-1300.

Pritchard, J. A., Wiggins, K. M., \& Dickey, J. C. (1962). Blood volume changes in pregnancy and the puerperium. American Journal of Obstetrics and Gynecology, 84(10), 1271-1282.

Razvi, K., Chua, S., Arulkumaran, S., \& Ratnam, S. S. (1996). A comparison between visual estimation and laboratory determination of blood loss during the third stage of labour. Australian and New Zealand Journal of Obstetrics and Gynaecology, 36(2), 152-154.

Rogers, J., Wood, J., McCandlish, R., Ayers, S., Truesdale, A., \& Elbourne, D. (1998). Active versus expectant management of third stage of labour: the Hinchingbrooke randomised controlled trial. Lancet, 351 (9104), 693-699. http://dx.doi.org/10.1016/s0140-6736(97)09409-9

Schorn, M. N. (2010). Measurement of blood loss: review of the literature. Journal of Midwifery \& Women's Health, 55(1), 20-27. http:// dx.doi.org/10.1016/j.jmwh.2009.02.014

Schrauwers, C., \& Dekker, G. (2009). Maternal and perinatal outcome in obese pregnant patients. The Journal of MaternalFetal \& Neonatal Medicine, 22(3), 218-226. http://dx.doi. org/10.1080/14767050902801652

Thilaganathan, B., Cutner, A., Latimer, J., \& Beard, R. (1993). Management of the third stage of labour in women at low risk of postpartum haemorrhage. European Journal of Obstetrics \& Gynecology and Reproductive Biology, 48(1), 19-22.

Wallace, G. (1967). Blood loss in obstetrics using a haemoglobin dilution technique. Journal of Obstetrics and Gynaecology of the British Commonwealth, 74(1), 64-67.

World Health Organization. (1996). Care in Normal Birth: A Practical Guide. Report of a Technical Working Group. Publication no. WHO/ FRH/MSM/96.24. Geneva: Author.

\section{Accepted for publication May 2017}

Oishi, T., Tamura, T., \& Yamamoto, U., (2017). Outcomes of blood loss post physiological birth with physiological management in the third stage of labour at a maternity home in Japan New Zealand College of Midwives Journal, 53, 23-29.

http://dx.doi.org/10.12784/nzcomin153.2017.3.23-29 